months following complete resolution of the symptoms of a first episode (Anderson et al, 2000).

Where the patient's condition warranted a specific intervention this was usually antidepressant medication. Antidepressant treatment was often the only treatment of proven efficacy that was offered to those who required more than watchful waiting or non-specific counselling. Nationally, there is evidence of long waitinglists for small numbers of mental health workers with training in specific psychological treatments, usually CBT (CSAG, 1999). There was little evidence to suggest that patients are offered a choice of treatment or interventions to promote concordance and self-management, such as psychoeducation or the use of patient information leaflets.

Studies of this kind depend on interviewees and their self-report rather than more robust methods such as direct observation of consulting behaviour. All responders were self-selected and therefore more likely to be interested in, and knowledgeable of, mental health issues. For these reasons, the results may represent higher than average standards, and reflect aspirations rather than actual practice. The findings reported here suggest GPs' knowledge of the assessment and management of depression, including effective prescribing of first- and second-line antidepressant medication, generally concurs with expert guidelines for effective intervention, although there may be scope for strengthening intervention during the continuation phase and withdrawal of pharmacological treatment. Although patients prefer psychological treatment to drug treatment, and ask for counselling, they usually exercise little choice in the intervention they receive.

\section{Declaration of interest}

None.

original papers

\section{References}

ANDERSON, I. M., NUTT, D. J. \& DEAKING, J. F.W. (2000) Evidence based guidelines for treating depressive disorders with antidepressants: a review of the 1993 British Association for Pharmacology Guidelines. Journal of

Psychopharmacology, 14(1), 3-20.

CLINICAL STANDARDS ADVISORY GROUP (1999) Services for People with Depression. London: Department of Health.

DEPARTMENT OF HEALTH (2001) Treatment Choice in Psychological Therapies and Counselling: Evidence Based Clinical Practice Guideline. London: HMSO

ECCLES, M., FREEMANTLE, N. \& MASON, J. (1999) North of England evidence-based guideline development project: summary version of guidelines for the choice of antidepressants for depression in primary care. Family Practice, 16, 103-111.

GOLDBERG, D. \& HUXLEY, P. (1992) Common Mental Disorders. A BioSocial Model. London: Routledge.

*Sarah Marriott Consultant Psychiatrist, Paterson Centre for Mental Health, 20 South Wharf Road, LondonW2 1EE， Christine Wright CSAG Research Assistant, Paul Lelliott Director, Royal College of Psychiatrists' Research Unit
KESSLER, R. C., ZHAO, S., BLAZER, D. G., et al (1997) Prevalence correlates and course of minor depression and major depression in the national comorbidity survey. Journal of Affective Disorders, 45, 19-30.

MARTIN, R. M., HILTON, S. R., KERRY S. M., et al (1997) General practitioners' perceptions about the tolerability of antidepressant drugs: a comparison between selective serotonin reuptake inhibitors and tricyclics. BMJ, 314 646-651.

MURRAY, C. J. \& LOPEZ, A. D. (1997) Alternate projections of mortality and disability by cause 1999-2020: global burden of disease study. Lancet, $\mathbf{3 4 9}$ 1498-1504.

OFFICE FOR NATIONAL STATISTICS (1996) The ONS Classification of Local and Health Authorities of Great Britain. London: HMSO

\title{
The relationship between medical school of training, age, gender and success in the MRCPsych examinations
}

\section{AIMS AND METHOD}

Factors leading to success in the MRCPsych Part I and Part II examinations, including age, gender and original medical school of training, were examined in the 1999 MRCPsych examination entrants to determine how far they are associated with the results. The ethnic breakdown of examiners of the MRCPsych examinations was also determined and compared with the origin of all consultant psychiatrists.

\author{
RESULTS \\ Younger age at taking the examina- \\ tion and training at a British or Irish \\ medical school were found to be \\ highly significant predictors of \\ success in the MRCPsych examina- \\ tions. When allowance was made for \\ confounding variables, the gender \\ of candidates did not contribute to \\ success. There was no difference \\ in ethnic background of examiners \\ compared with consultant \\ psychiatrists overall.
}

\author{
CLINICAL IMPLICATIONS \\ Factors affecting trainees wishing to \\ undertake a psychiatric career need \\ to be more closely examined. To \\ ensure fairness and transparency in \\ future examinations the ethnicity of \\ candidates taking the examination \\ needs to be addressed.
}

\section{Introduction}

The Membership examination of the Royal College of Psychiatrists (MRCPsych) is scrutinised regularly by an examinations monitoring panel - a group of senior examiners and educators who are appointed by the College's senior academic committee, the Court of Electors. All parts of the examination are reviewed carefully. 
The Court of Electors has agreed that details of relevant data and analyses should be made available, not only to those involved in the exercise but also to others inter-

original papers ested in the examination process. This should assist candidates and examiners and increase the transparency of the examination process. Those who are proposing to take the examinations need to be assured that candidates are assessed fairly and discrimination on whatever basis does not occur. Some details of the performance of candidates in the MRCPsych examinations have been given previously (Royal College of Psychiatrists, 1999), but no systematic analysis has been published. The particular areas in which interest has been expressed are gender, ethnicity and age.

\section{Gender}

In undergraduate medical examinations in the UK, female students have been found to perform significantly better than men (Pritchard, 1988). McManus et al (1996) showed that male medical students were 1.65 times more likely to fail at least one of their final examinations than female students. Likewise, Acheson (1997) found that male undergraduate students at Belfast were over three times as likely to fail the final examinations than their female counterparts. McDonough et al (2000) showed that female medical students at Dublin were significantly more likely to achieve honours standard in the final psychiatry examinations than their male peers. The success rate in the Japanese national examination for medical practitioners is significantly higher for females than males (93.5\% v. 86.3\%; Matsubayashi, 1997). In the USA, women medical students outperformed men in obstetrics and gynaecology examinations (Krueger, 1998).

There are less data on gender differences in performance in postgraduate examinations, but the studies performed also support predominant female success. Women had a higher pass rate than men in Part I of the Faculty of Public Health Medicine examination (Ayres et al, 1996). After graduation, female general practitioners (GPs) have been found to have a higher quality of recordkeeping than their male colleagues (Del Mar et al, 1996).

The reason for this consistent gender difference is not entirely clear. It has been suggested that women may be more diligent in their studies (Acheson, 1997). Skelton and Hobbs (1999) studied the gender differences in consultation styles among GPs, and suggested that men may find it harder to develop a cooperative approach to doctor-patient interactions. They suggested that cooperative language might be more typical of female speech style. The better social and empathic skills of women may account for their better performance in specialities like psychiatry, where doctor-patient interaction plays a key role in diagnosis and management. This may be of particular importance in clinical examinations in this discipline.

\section{Ethnicity}

There is evidence that the place of medical school training is an important factor in determining success in post- graduate examinations. Although it would be expected that the majority of candidates that trained at UK and Irish medical schools would be White and of Caucasian background, a significant proportion of graduates is from other ethnic backgrounds.

Esmail et al (1995) showed that $18 \%$ of medical students admitted to British medical schools were of non-Caucasian background. McManus et al (1996) found that the pass rate at the final medical examinations in a large British medical school was higher for medical students from non-UK backgrounds than in White students from the UK. Wakeford et al (1992) found that Asian doctors performed less well than non-Asians in all parts of the Membership of the Royal College of GPs' (MRCGP) examination, but this was largely owing to poor performance of Asian doctors born and trained outside the UK. Those born and trained in the UK performed similarly to the non-Asian doctors.

\section{Age}

The effect of age on examination success has not been investigated in UK examinations. However, Mick and Mou (1991), in an analysis by logistic regression, showed that the strongest factors predicting successful results in the Foreign Medical Graduate Examination in the Medical Sciences (FMGEMS; the basic medical examination for foreign graduates in USA) were age of taking the examination being under 30 years and native English speech.

In the present study, the gender, age and country of original medical school of all candidates entering both parts of the MRCPsych examination in 1999 were studied in relation to pass rate. In addition, the ethnicity and gender of all examiners were compared with those of College Members eligible to become examiners.

\section{Results}

\section{Part I examination}

The distribution of candidates taking the Part I examination, categorised according to medical school, pass rate and gender, is indicated in Table 1. Only candidates who pass the multiple choice question (MCQ) paper proceed to the clinical examination.

\section{Medical school of training and gender}

The results indicate that the pass rate is significantly higher for candidates who have trained at medical schools in the UK or Ireland (hereinafter referred to as the UK/Ireland Group), in comparison with both those graduating from the Indian subcontinent (referred to as the Indian group for convenience: $\chi^{2}=85.0$; d.f. $=1$; $P=<0.0001)$ and to those graduating from medical schools in Europe and elsewhere (the rest of the world group: $\chi^{2}=81.6$; d.f. $\left.=1 ; P=0.001\right)$. This difference is shown for both the MCQ (UK/Irish v. Indian: $\chi^{2}=37.8$; d.f. $=1 ; P=<0.001$; UK/Irish $v$. rest of world: $\chi^{2}=18.4$; d.f. $=1 ; P=<0.001$ ) and for the clinical examination (UK/ Irish v. Indian: $\chi^{2}=51.3$; d.f. $=1 ; P=<0.001$; UK/Irish $v$. rest of world: $\chi^{2}=69.4 ;$ d.f. $\left.=1 ; P=<0.0001\right)$. There is no 
Table 1. The distribution of candidates taking the Part I examination according to medical school of training, gender and pass rate

\begin{tabular}{|c|c|c|c|c|c|c|c|c|}
\hline \multirow[b]{2}{*}{ Group } & \multirow[b]{2}{*}{ Medical school } & \multicolumn{3}{|c|}{ MCQ } & \multirow[b]{2}{*}{ Candidates taking clinical } & \multicolumn{2}{|c|}{ Total pass rate } & \multirow[b]{2}{*}{ Total pass rate (\%) } \\
\hline & & Females & Males & Total & & Females (\%) & Males (\%) & \\
\hline \multirow{2}{*}{ A } & RI & 35 & 30 & 65 & 35 & $17(49)$ & $12(40)$ & $29(45)$ \\
\hline & Subtotal & 211 & 199 & 410 & 305 & $133(63)$ & $127 \quad(64)$ & $260(63)$ \\
\hline B & Subtotal & 59 & 256 & 315 & 165 & $24(41)^{\star}$ & $67 \quad(26)$ & $91(29)$ \\
\hline \multirow[t]{9}{*}{ C } & EUR & 12 & 23 & 35 & 23 & $5(42)$ & $7 \quad(30)$ & $12(34)$ \\
\hline & $\mathrm{EC}$ & 70 & 57 & 127 & 67 & $17(24)$ & $15 \quad(26)$ & $32(25)$ \\
\hline & ANZ & 2 & 2 & 4 & 3 & $1(50)$ & $2(100)$ & $3(75)$ \\
\hline & SA & 16 & 28 & 44 & 32 & $9(56)$ & $14(50)$ & $23(52)$ \\
\hline & CAM & 4 & 1 & 5 & 3 & $1(25)$ & $1(100)$ & $2(40)$ \\
\hline & NA & 12 & 26 & 38 & 16 & 1 (8) & $6 \quad(23)$ & $7(18)$ \\
\hline & SAM & 0 & 3 & 3 & 3 & 0 & $2(67)$ & $2(67)$ \\
\hline & Subtotal & 150 & 253 & 403 & 243 & $44(29)$ & $84 \quad(33)$ & $128(32)$ \\
\hline & Totals & 420 & 708 & 1128 & 713 & $201(48)^{\star *}$ & $278 \quad(39)$ & $479(42)$ \\
\hline
\end{tabular}

original papers

$* P=<0.05 \quad * * P=<0.01$.

MCQ: multiple choice questions; RI: Republic of Ireland; IB: Indian Borders; IS: Indian Subcontinent; EUR: Non-EC European countries; EC: European countries; ANZ: Australia and New Zealand; SA: South Africa; ME: Middle East; SEA: South East Asia; CA: Central Africa; CAM: Central America; NA: North Africa; SAM: South America.

difference between the pass rate of candidates from the Indian group compared with the rest of the world group $\left(\chi^{2}=0.37\right.$; d.f. $\left.=1, P=>0.5\right)$. The pass rate is higher for women than men $\left(\chi^{2}=7.97\right.$; d.f. $=1 ; P=<0.005$; odds ratio $=1.4(95 \% \mathrm{Cl}, 1.1-1.8))$. This gender difference is explained entirely by the relatively high failure rate of male candidates who qualified from medical schools from the Indian subcontinent $\left(\chi^{2}=4.9\right.$; d.f. $=1 ; P=0.03$; odds ratio $=1.93(95 \% \mathrm{Cl}, 1.07-3.49))$. There is no significant difference in pass rate according to gender from any other country or geographically distinct group of countries, although the numbers are small. In particular, the male and female pass rate from the UK/Ireland group is virtually identical (63\% female, $64 \%$ male).

\section{Age and time since qualification}

Those who passed the examination were significantly younger than those who failed (31.0 years $v$. 34.2 years, independent $T$-test, $T=9.41$ ) and had qualified for a significantly shorter period of time (5.9 years $v .8 .1$ years; independent $T$-test, $T=7.68, P<0.0005)$. The UK/Ireland candidates were significantly younger than both the Indian group (30.2 v. 34.0 years; independent T-test, $T=9.70)$ and the rest of the world group (30.2 v. 34.6 years; independent $T$-test, $T=12.2$ ). The UK/Ireland candidates had qualified for a significantly shorter period of time than the Indian group (5.0 v. 8.3 years; independent $T=$ test, $T=10.0$ ) and the rest of the world group (5.0 v. 8.4 years; independent $T$-test, $T=10.7$ ). All these $T$-tests are highly significant, with $P=\leqslant 0.0005$ for each $T$-value. There was no significant difference in either age or time since qualification between male and female candidates.
In view of the confounding effects of the variables of age, time since qualification and previous number of attempts at the examination on the pass rate by gender, the effects of these variables were examined further. Logistic regression was therefore carried out with the examination result as the dependent variable and gender, ethnicity, age, time since qualification and the number of attempts at taking the examination as five independent variables. This last variable was included as the candidates who fail the examination will on average be older than those taking it for the first time. This multivariable analysis showed that passing the MRCPsych Part I was significantly associated with both graduation from a UK or Irish Medical School $(P=<0.0002)$ and a younger age $(P=<0.00001)$. Gender, years since qualification and number of attempts at the examination were not statistically significant ( $P>0.05$ for all three variables) after adjusting for school of graduation and age.

\section{Part II examination}

A similar pattern is shown in the Part II examination (see Table 2).

\section{Medical school of training and gender}

The results indicate that the pass rate is significantly higher for graduates from the UK/Irish group compared with the Indian group $\left(\chi^{2}=72.2 ;\right.$ d.f. $\left.=1 ; P=<0.0001\right)$ and the rest of the world group $\left(\chi^{2}=84.7\right.$; d.f. $=1$, $P=<0.0001)$. There is no difference between the pass rate of candidates from the Indian group compared with the rest of the world group $\left(\chi^{2}=0.90 ;\right.$ d.f. $=1 ; P=>0.3$ ). A greater proportion of women than men are also 
Table 2. The distribution of candidates taking the Part Il examination according to medical school of training and pass rate

original papers

\begin{tabular}{|c|c|c|c|c|c|c|c|}
\hline \multirow[b]{2}{*}{ Group } & \multirow{2}{*}{$\begin{array}{l}\text { Medical } \\
\text { School }\end{array}$} & \multicolumn{3}{|c|}{ Number of candidates } & \multicolumn{2}{|c|}{ Gender pass rate } & \multirow{2}{*}{$\begin{array}{c}\text { Total pass rate } \\
(\%)\end{array}$} \\
\hline & & Female & Male & Total & Female (\%) & Male (\%) & \\
\hline \multirow[t]{3}{*}{ A } & UK & 184 & 171 & 355 & $131(71)$ & $110(64)$ & $241(68)$ \\
\hline & $\mathrm{RI}$ & 30 & 21 & 51 & $16(53)$ & $11(52)$ & $27(53)$ \\
\hline & Subtotal & 214 & 192 & 406 & $147(69)$ & $121(63)$ & $268(66)$ \\
\hline \multirow[t]{3}{*}{ B } & IB & 7 & 24 & 31 & $2(29)$ & $3(13)$ & $5(16)$ \\
\hline & IS & 23 & 67 & 90 & $8(35)$ & $14(21)$ & $22(24)$ \\
\hline & Subtotal & 30 & 91 & 121 & $10(33)$ & $17(19)$ & $27(22)$ \\
\hline \multirow[t]{11}{*}{ C } & EUR & 10 & 10 & 20 & $2(20)$ & $2(20)$ & $4(20)$ \\
\hline & EC & 18 & 23 & 41 & $4(22)$ & $8(35)$ & $12(29)$ \\
\hline & ANZ & 2 & 6 & 8 & $1(50)$ & $4(66)$ & $5(63)$ \\
\hline & SA & 9 & 15 & 24 & $6(66)$ & $6(40)$ & $12(50)$ \\
\hline & ME & 4 & 6 & 10 & 0 & $3(50)$ & $3(30)$ \\
\hline & SEA & 11 & 19 & 30 & $5(45)$ & $11(58)$ & $16(53)$ \\
\hline & CA & 15 & 61 & 76 & $4(27)$ & $6(10)$ & $10(13)$ \\
\hline & NA & 3 & 22 & 25 & $1(33)$ & $3(14)$ & $4(16)$ \\
\hline & SAM & 0 & 2 & 2 & 0 & $1(50)$ & $1(50)$ \\
\hline & Subtotal & 72 & 164 & 236 & $23(32)$ & $44(27)$ & $67(28)$ \\
\hline & Total & 316 & 447 & 763 & $180(57)^{\star *}$ & $182(41)$ & $362(47)$ \\
\hline
\end{tabular}

$* * P=<0.01$

RI: Republic of Ireland; IB: Indian Borders; IS: Indian Subcontinent; EUR: Non-EC European countries; EC: European countries; ANZ: Australia and New Zealand; SA: South Africa; ME: Middle East; SEA: South East Asia; CA: Central Africa; CAM: Central America; NA: North Africa; SAM: South America.

successful in this part of the examination $\left(\chi^{2}=18.4\right.$; d.f. $=1 ; P=<0.001)$. As in the Part I examination, this gender difference is explained to a degree by the relatively high failure rate of male candidates who qualified from medical schools from the Indian subcontinent, but this does not reach significance. There is again no difference between the gender ratio of candidates from Irish and UK medical schools.

\section{Age and time since qualification}

Those who passed the Part II examination were again significantly younger than those who failed (mean 32.0 years $v$. 34.8 years; independent $T$-test, $T=7.51$; $P=\leqslant 0.0005)$ and had qualified for a significantly shorter period of time (mean 7.3 years v. 9.4 years; independent $T$-test, $T=6.37 ; P \leqslant 0.0005)$. There were also differences in the ages of the candidates according to the medical school of training. The candidates from the UK and Ireland were significantly younger than those from the Indian subcontinent (31.6 v. 35.6 years; independent $T$-test, $T=9.07 ; P=<0.0005)$ and the rest of the world group (31.6 v. 36.1 years; independent $T$-test, $T=11.4$;

$P=<0.0005)$. UK/Irish candidates had qualified for a significantly shorter period of time than the Indian group of candidates ( $6.8 \mathrm{v}$. 10.1 years; independent $T$-test, $T=8.45 ; P=<0.005)$ and the rest of the world group (5.0 v. 10.4 years; independent $T$-test, $T=10.5, P=<0.0005$ ). Male candidates were significantly older than female candidates (34.3 v. 32.6 years; independent $T$-tests, $T=4.5 ; P=<0.0005)$ and qualified for longer (8.9 v. 7.7 years; independent $T$-test, $T=3.7 ; P=<0.0005)$.

In view of the interrelationship of the variables concerned, logistic regression was again performed with the examination result as the dependent variable and the same five factors used for the Part I examination as the independent variables. This multivariable analysis illustrated that passing the MRCPsych Part II examination was significantly associated with training at a UK or Irish medical school $(P=\leqslant 0.0001)$ and younger age $(P=\leqslant 0.006)$. Gender and years since qualification ( $P>0.05$ for both variables) were not statistically significant after adjusting for place of medical school training and age. This was also the case when allowing for those candidates who had multiple attempts. The failure rate increased at each subsequent attempt but the numbers of candidates involved were small (see Table 3).

Table 3. Relationship between the number of attempts at the Part II examination and pass rate

\begin{tabular}{lrrr} 
Number of attempts & $\begin{array}{c}\text { Number who } \\
\text { failed }\end{array}$ & $\begin{array}{c}\text { Number who } \\
\text { passed }\end{array}$ & Total \\
\hline 1 & 221 & 233 & 454 \\
2 & 100 & 88 & 188 \\
3 & 51 & 33 & 84 \\
4 & 18 & 7 & 25 \\
5 & 10 & 1 & 11 \\
6 & & 1 & 1 \\
Total & & & 763 \\
\end{tabular}

Unadjusted pass rate for: 1st attempt: $233 / 454=51 \%$; 2nd attempt: 88 / $188=46.8 \%$; 3rd attempt: $33 / 84=39.2 \%$; 4 th attempt: $7 / 25=28 \%$; 5 th attempt: $1 / 11=9 \%$.

This analysis was carried out without adjusting for other factors. Although there appears to be a significantly greater chance of failing the examination the more attempts that have been made, using multiple regression and adjusting for years since qualification, gender, ethnicity and age, the number of attempts was no longer a significant factor. 


\section{Gender and ethnicity of examiners}

One element in ensuring an ethnically fair examination is for ethnic groups to be fairly represented among examiners. More than 25\% of consultant psychiatrists registered with the Royal College of Psychiatrists were not born in the UK. The ethnic origin of MRCPsych examiners was viewed to determine if there was overrepresentation of any ethnic group. Tables 4 and 5 indicate the gender and ethnicity of all Part I and Part II examiners compared with all those College Members and Fellows of consultant grade aged between 40 and 60 .

It can be seen that there is a good match between the proportion of examiners according to group of ethnic origin compared with those who are not examiners. This conclusion is, however, limited by the fact that just over $20 \%$ of examiners and Members have not declared their ethnic origin. We also looked at the gender breakdown of

Table 4. Breakdown by ethnic origin and gender of MRCPsych Part I and Part II examiners

\begin{tabular}{lcc}
\hline Ethnic group & Part I board (\%) & Part II board (\%) \\
\hline White & $102(68)$ & $108(64.7)$ \\
Black Caribbean & - & - \\
Black African & - & $1(0.6)$ \\
Black other & - & - \\
Indian & $12(8)$ & $15(8.9)$ \\
Pakistani & - & $2(1.2)$ \\
Bangladeshi & - & - \\
Chinese & - & 1 \\
Other - Asian & $3(2)$ & $5(2.9)$ \\
Other - non-Asian & $3(2)$ & $78(21.0)$ \\
Undeclared & $30(20)$ & 167 \\
Total & 150 & $132(79)$ \\
$\quad$ Male & $105(70)$ & $35(21)$ \\
Female & $45(30)$ & \\
\hline
\end{tabular}

Table 5. Breakdown by ethnic origin and gender of College

Members aged $40-60$ of currently registered consultant NHS psychiatrists in UK and Irish Republic

\begin{tabular}{|c|c|c|c|c|}
\hline Ethnic group & Male & Female & Total & $\begin{array}{c}(\%) \text { of } \\
\text { total } \\
\text { psychia- } \\
\text { trists }\end{array}$ \\
\hline White & 924 & 603 & 1527 & 63.2 \\
\hline Black Caribbean & 2 & 1 & 3 & 0.1 \\
\hline Black African & 18 & 2 & 20 & 0.8 \\
\hline Black other & 1 & 0 & 1 & 0.04 \\
\hline Indian & 129 & 42 & 171 & 7.0 \\
\hline Pakistani & 22 & 3 & 25 & 1.0 \\
\hline Bangladeshi & 6 & 3 & 9 & 0.4 \\
\hline Chinese & 9 & 2 & 11 & 0.5 \\
\hline Other - Asian & 42 & 18 & 60 & 2.5 \\
\hline Other - non-Asian & 41 & 7 & 48 & 2.0 \\
\hline Undeclared & 362 & 178 & 540 & 22.0 \\
\hline Total & 1556 & 859 & 2415 & \\
\hline Percentage & $64 \%$ & $36 \%$ & $100 \%$ & \\
\hline
\end{tabular}

examiners compared with that of the College Membership as a whole. There are disproportionately less female examiners than expected and this reaches significance for the Part II board of examiners $\left(\chi^{2}=16.7\right.$; d.f. $=1$; $P=<0.001$; odds ratio $=2.2 ; \mathrm{Cl}, 1.5-3.2)$.

\section{Discussion}

The results show that medical school of training and older age at the time of taking the examination are highly significantly related to performance in both parts of the MRCPsych examination. Our findings are largely similar to those of Wakeford et al (1992), but information on the precise ethnic background of the candidates is not, at present, recorded at the time candidates enter the examination. Therefore, the results do not necessarily indicate that candidate ethnicity is directly related to performance.

Nevertheless, the results do indicate that there is a higher rate of failure in male candidates who are trained in medical schools on the Indian subcontinent compared with male candidates who are trained elsewhere. It is also clear that the pass rate among Indian female graduates is higher than Indian males. Although this is related to the fact that the age of Indian men taking the examination is older than their female counterparts, this is not the only explanation because the failure rate in the Indian men is greater when accounting for their later age of taking the examination. Possible explanations include later decision when to take the MRCPsych examination and reasons for choosing psychiatry as a career speciality.

Although the age at which medical students graduate from overseas medical schools is a little later than the majority of British medical schools, this is insufficient to explain why overseas male postgraduates are more likely to take the MRCPsych examinations at a substantially older age than others. There is no reason to suppose there is a difference between the age of females and males graduating from Indian medical schools, although the authors have no direct information on this topic. Other factors, therefore, are likely to play a part. It has been reported that a number of doctors who come to the UK to seek specialist qualifications opt for psychiatry as a career choice when they fail to obtain a post in some of the more popular specialities (Brook, 1981; Sridhar, 2000), including medicine, paediatrics and obstetrics and gynaecology. This could be a factor in explaining a high failure rate among doctors who have chosen psychiatry as a second option later in their career. We do not know enough about whether women from the Indian subcontinent are more likely to choose psychiatry as a first option.

This issue is relevant as many overseas graduates have difficulty in obtaining a training post in the popular specialities, even after passing the Professional and Linguistic Assessment Board (PLAB) test conducted by the General Medical Council (Welsh, 2000; Buchanan \& Smith, 2001). Although all those taking the PLAB test are advised that success in this examination does not guarantee a post on a training programme, many original papers 


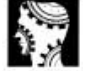

original papers postgraduates believe that it will enable them to obtain a training post. Sridhar (2000) plangently describes the problems that successful PLAB candidates have in gaining a post in the speciality of their choice, some of who 'move into psychiatry simply to earn a living'.

Roberts et al (2000) investigated the ethnic differences in performance in the MRCGP oral examination, and found that Asian candidates may be disadvantaged by the mixture of types of discourse (i.e. personal, professional and institutional) required in the different parts of this examination, as well as their linguistic features (e.g. high tolerance of digression in the way information is structured). They recommended that examiners should be sensitised to the issues. Examination boards need to publish examples of oral questions with examples of candidates' answers and examiners' comments. Examiners also need guidance on how to make explicit the intention of their questions and avoid shifting frames unexpectedly. The complexity of such interactions and discourse is common to both general practice and psychiatry. The introduction of an observed structured clinical examination (OSCE) element in the MRCPsych Part I examination from Spring 2003 should help to reduce this problem. Greater standardisation of the problems posed in the 'patient management problems' part of the Part II examination, with production of standard questions, will further inform prospective candidates and reduce potential linguistic bias.

Our conclusions regarding ethnicity are limited by lack of direct knowledge of candidates' ethnic background and our use of undergraduate medical school as a surrogate marker. Plans have now been put in place to look directly at the relationship of ethnicity and examination success. The College is committed to having external scrutiny of ethnic and cultural fairness in all parts of the MRCPsych examination and, indeed, in all aspects of the College's activities (Cox, 2001)

It is possible that the findings illustrated here are associated with the wide spectrum of doctors taking the MRCPsych examinations and are less likely to be shown in more homogeneous medical specialities. However, Mick and Mou (1991), as mentioned previously, showed that the strongest factors predicting successful results in the FMGEMS were age of over 30 years and native English speaking. There may be some parallels here between the two examinations.

Although these results show that the overall pass rates in both Part I and Part II examinations are significantly higher for women than men, this is explicable by other confounding variables. In the Part I examination, this gender imbalance in performance was owing to the poor pass rate of male candidates from the Indian subcontinent. These male candidates are older than the average candidate taking the examination, irrespective of gender, and later age at the time of taking the examination is highly significantly related to failure. A similar pattern, although not quite so marked, is shown in the Part II examination.

It is nevertheless inappropriate to assume that the high failure rate among non-UK and Irish candidates is simply due to older age alone at the time of taking the
MRCPsych examination. Although the age at which candidates take the MRCPsych examination is clearly an important factor in predicting success, there are other factors that relate to age of entering the MRCPsych examination that affect the interpretation of these results. These include success or failure in previous undergraduate or postgraduate examinations, the timing of the decision to make a choice about a future postgraduate career in psychiatry and age of entering medical school. It may be that female medical graduates from medical schools other than British or Irish start their training earlier, are more successful in passing the stages in the training process and decide early to enter psychiatry. This information is not available from the data recorded on this group of candidates taking the examination.

The information in Table 3 illustrates that the more attempts that candidates make at the examination, the less likely they are to pass. However, on multiple regression analysis, adjusting for year of qualification, gender, ethnicity and age, the number of attempts of taking the examination did not become a significant factor in contributing to success or failure in the examination. None the less, those candidates taking the exam on two or more occasions should be offered greater support from training scheme coordinators. Practice in mock examinations and development of management techniques should be offered. Sponsoring tutors and educational supervisors are being urged to offer guidance in this regard both to training scheme coordinators and candidates.

\section{Conclusions}

The performance of candidates in the MRCPsych examinations is closely related to where training was received at medical school and the age at which the examination is attempted. The results illustrating the profound effects of medical school training and age have persuaded us to look in more detail at the reasons for these differences in pass rates. As a result, candidates will in future be asked to give their ethnic origin so that a clearer picture of the effect of training can be obtained. The reasons for trainees selecting this speciality also require more enquiry.

More female consultants of appropriate calibre should be encouraged to join the Part II board of examiners. The large number of overseas candidates taking the MRCPsych examination emphasises the necessity to ensure that the College examination procedures provide a fair test for all candidates entering the examination.

\section{Declaration of interest}

None.

\section{References}

ACHESON, A. G. (1997) Do male students face prejudice? Lancet, $\mathbf{3 5 0}$ 964.

AYRES, P, RIGBY, A. S. \& WILLIAMS, R. (1996) Part I of Membership of the Faculty of Public Health Medicine 
(MFPHM). Trends over time and factors associated with success in recent years. Journal of Public Health Medicine, 18 390-395.

BROOK, P. (1981) The choice of career of consultant psychiatrists. British Journal of Psychiatry, 138, 326-328.

BUCHANAN, D. J. \& SMITH, G. (2001)

Training overseas doctors in the United Kingdom. BMJ, 322, 109

COX, J. L. (2001) Commentary: institutional rationalism in British psychiatry. Psychiatric Bulletin, 25, 248-249.

DEL MAR, C., LOWE, J. B., ADKINS, P., et al (1996) What is the quality of

general practitioner records in

Australia? Australian Family Physician,

Suppl 1, S21-S25.

ESMAIL, A., NELSON, P., PRIMAROLO,

D., et al (1995) Acceptance into medical school and racial discrimination. BMJ, 310, 501-502.

KRUEGER P. M. (1998) Do women medical students outperform men in obstetrics and gynecology? Academic Medicine, 73(1), 101-102.

MATSUBAYASHI, K. (1997) Sex and examination results. Lancet, 350, 1711. MCDONOUGH, C. M., HORGAN, A. CODD, M. B., et al (2000) Gender differences in the results of the final medical examination of University

College Dublin. Medical Education, 34 30-34.

MCMANUS, I. C., RICHARDS, P., WINDER, P. C. et al (1996) Final examination performance of medical students from ethnic minorities. Medical Education, 30, 195-200.

MICK, S. S. \& MOU, T. W. (1991) The Foreign Medical Graduate
Examination in the Medical Sciences

SKELTON, J. R. \& HOBBS, F. D. R. (1999)

(FMGEMS). An analysis of pass rates of the July 1984 through July 1987 examinations. Medical Care, 29 229-242.

escriptive study of $\mathrm{CO}$-operative language in primary care consultations by male and female doctors. BMJ, $\mathbf{3 1 8}$ $576-579$.

PRITCHARD, D. J (1988) Effects of sex and alphabetical listing on examination performance of medical students. Medical Education, 22(3), 205-210.

ROBERTS, C., SARANGI, S., SOUTHGATE, L., et al (2000) Oral examinations, equal opportunities, ethnicity, and fairness in the MRCGP. BMJ, 320, 370-375.

ROYAL COLLEGE OF PSYCHIATRISTS (1999) Examination results. Psychiatric Bulletin, 23,623-626.

*S. P. Tyrer Chief Examiner, Royal College of Psychiatrists, W.-C. Leung Lecturer in Public Health Medicine, University of EastAnglia, J. Smalls formerly Head of Examination Services, Royal College of Psychiatrists, C. Katona Dean, Royal College of Psychiatrists, 17 Belgrave Square, London SW1X 8PG 